06

\title{
К вопросу об устойчивости метастабильной $\omega$-фазы в псевдомонокристаллическом цирконии
}

\author{
(С) Л.Ю. Егорова, Ю.В. Хлебникова, В.П. Пилюгин \\ Институт фризики металлов им. М.Н. Михеева УрО РАН, \\ 620108 Екатеринбург, Россия \\ e-mail:egorova@imp.uran.ru
}

Поступило в Редакцию 19 марта 2019 г.

В окончательной редакции 19 марта 2019 г.

Принято к публикации 21 мая 2019 г.

В камере Бриджмена при температурах $20,70,100,300^{\circ} \mathrm{C}$ и при одинаковой схеме нагружения испытаны образцы псевдомонокристалла циркония. Испытания проводились с целью исследования возможности сохранения метастабильной $\omega$-фазы при повышенных температурах. Исследования показали, что в процессе теплой деформации, в результате образования равновесных межфазных границ и ориентированного зарождения и роста $\omega$-фазы возникают стабильные структурные конфигурации, которые способствуют повышению устойчивости $\omega$-фазы после охлаждения и снятия нагрузки. В образце, испытанном при $300^{\circ} \mathrm{C}$, обнаружены дисперсные частицы гидрида циркония переменного состава $-\delta-\mathrm{ZrH}_{2-x}$, которые обусловливают высокую твердость, сравнимую с твердостью образца, подвергшегося испытаниям при комнатной температуре.

Ключевые слова: псевдомонокристалл циркония, мегапластическая теплая деформация, высокое квазигидростатическое давление, $\alpha \leftrightarrow \omega$-фазовые переходы, рекристаллизация.

DOI: $10.21883 /$ JTF.2020.01.48669.98-19

\section{Введение}

Цирконий благодаря своим уникальным свойствам нейтронной прозрачности, прочности и высокой коррозионной стойкости - незаменимый конструкционный материал для атомных реакторов и ядерных установок. Поскольку сплавы Zr в энергетических реакторах работают под давлением при температуре около $300^{\circ} \mathrm{C}[1]$, к качеству изготовляемых циркониевых оболочек (твэлов) предъявляются повышенные требования.

Известно [2], что цирконий имеет три кристаллические модификации: высокотемпературную $\beta$-ОЦК фазу, низкотемпературную $\alpha$-ГПУ фазу и метастабильную $\omega$-ГП фазу, которая может образовываться как в результате закалки из $\beta$-фазы в легированных сплавах, так и под воздействием давления из $\alpha$-фазы.

В отличие от стабильных модификаций $\omega$-фаза обладает повышенной твердостью и прочностью, а значит и хрупкостью, поэтому неконтролируемое появление этой фазы в структуре материала, подвергаемого экстремальным нагрузкам, крайне нежелательно, так как может спровоцировать аварийную ситуацию.

На сегодняшний день недостаточно исследован вопрос о стабильности барической $\omega$-фазы, образовавшейся в разных термических условиях. В связи с этим с целью изучения влияния температуры на образование и эволюцию структуры барической $\omega$-фазы, в настоящей работе были проведены исследования псевдомонокристаллического циркония, испытанного в камере Бриджмена при различных температурах.

\section{Материалы и методика эксперимента}

В настоящей работе испытаниям подвергали образцы иодидного псевдомонокристаллического $\alpha$-циркония чистотой $99.9 \%$, полученного методом бестигельной электронно-лучевой зонной плавки. Деформацию дисковых образцов осуществляли в камере Бриджмена при давлении $8 \mathrm{GPa}$ с угловой скоростью $\omega=0.105 \mathrm{rad} / \mathrm{s}$. Угол поворота наковален для всех образцов составлял $\varphi=1080 \mathrm{deg}$. Испытания проводили при комнатной температуре, а также при температурах 70, 100 и $300^{\circ} \mathrm{C}$. Нагрев образца происходил совместно с блоком наковален с помощью специальной печи, контроль температуры осуществляли с помощью термопары, присоединенной к неподвижной наковальне. Испытания начинали по достижении заданной температуры. Время от окончания деформации до извлечения образца на воздух составляло не более $120 \mathrm{~s}$.

Степень истинной деформации (e) рассчитывали на середине радиуса образца по формуле [3]

$$
e_{\text {true }}=2 / \sqrt{3} \cdot \ln \left(1+\left(\varphi \cdot r / h_{f}\right)^{2}\right)^{1 / 2}+\ln h / h_{0},
$$

где $\varphi$ - угол поворота наковален в камере Бриджмена, $r$ - расстояние, равное середине радиуса образца, $h_{0}-$ начальная толщина образца, $h_{f}$ - толщина образца после испытания в камере Бриджмена.

Размер зерен определяли по серии электронно-микроскопических снимков методом секущих. Количество измеряемых структурных элементов при этом было не менее 80.

Измерения микротвердости проводили на середине радиуса образца с помощью микротвердомера ПМТ-3. 

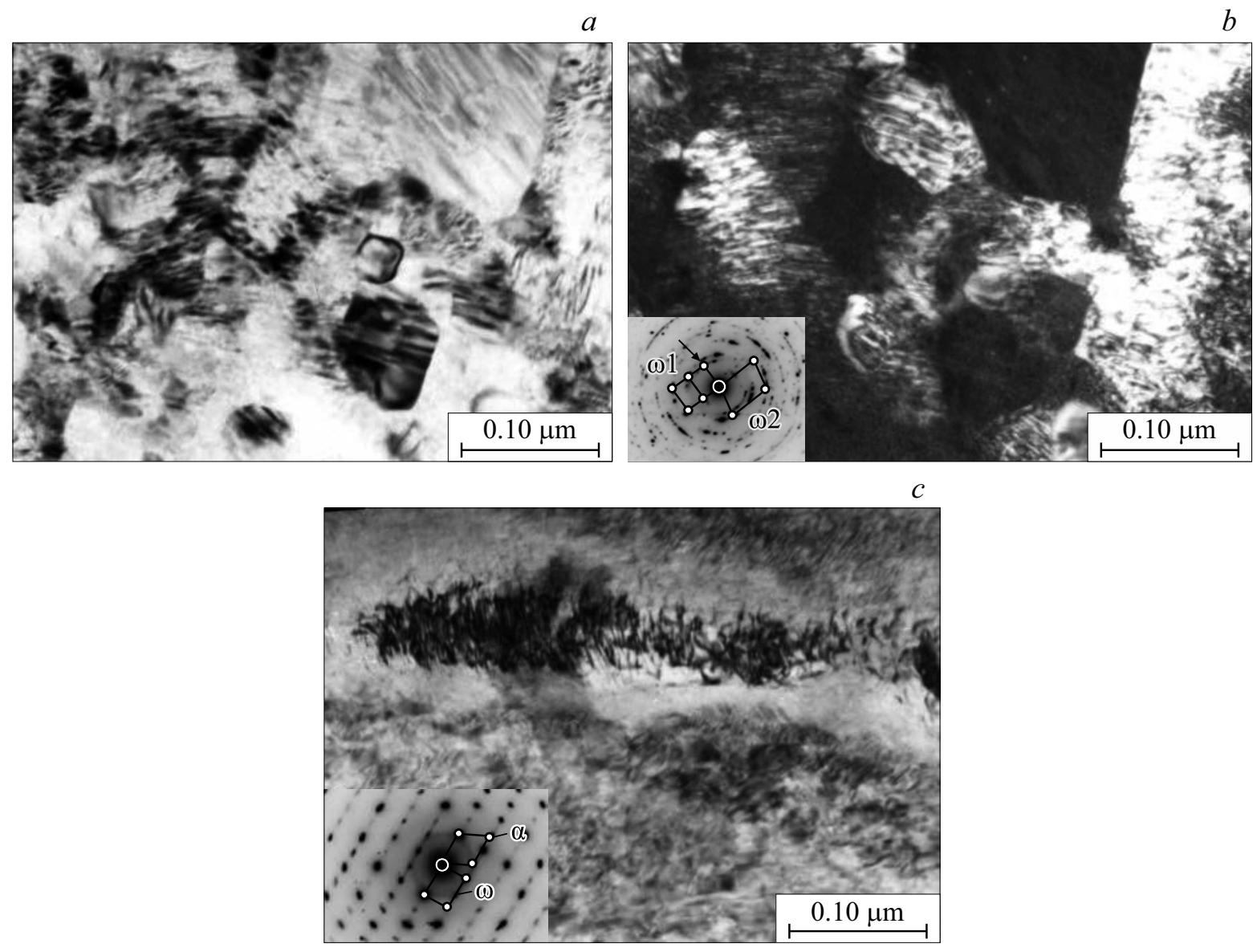

Рис. 1. Микроструктура $\mathrm{Zr}$, продеформированного при $T_{\mathrm{test}}=70^{\circ} \mathrm{C}: a-$ светлопольное изображение типичной структуры; $b-$ темнопольное изображение в $g_{\omega 1}=001$ оси зоны $[010]_{\omega 1}$ (показан стрелкой); $c$ - светлопольное изображение реечной структуры. Обратные решетки с осью зоны $[101]_{\alpha}$ и с осью зоны $[120]_{\omega}$ (показаны схемой на рис. $1, c$ ).

Структурно-фазовое состояние образцов циркония после деформации исследовали электронно-микроскопически на просвет тонких фольг в микроскопе JEM-200CX.

\section{Результаты эксперимента и их обсуждение}

В таблице представлены значения микротвердости $(\mathrm{HV})$, истинной деформации $\left(e_{\text {true }}\right)$ и средний размер структурных элементов $(d)$ образцов псевдомонокристаллического циркония, испытанных в камере Бриджмена при различных температурах. Видно,

Механические свойства

\begin{tabular}{r|c|c|l|c}
\hline$T_{\text {test. }},{ }^{\circ} \mathrm{C}$ & $\varphi, \mathrm{deg}$ & $\mathrm{HV}, \mathrm{MPa}$ & $e_{\text {true }}$ & $\begin{array}{c}d, \text { средний размер струк- } \\
\text { турных элементов, } \mu \mathrm{m}\end{array}$ \\
\hline 20 & 1080 & 3600 & 7 & $0.01-0.1$ \\
70 & 1080 & 4200 & 8.5 & $0.05-0.2$ \\
100 & 1080 & 3300 & 9.1 & $0.02-0.2$ \\
300 & 1080 & 3300 & 8 & $0.2-1.0$
\end{tabular}

что микротвердость образцов циркония при повышении температуры барадеформационной обработки от 20 до $70^{\circ} \mathrm{C}$ увеличивается, несмотря на то, что средний размер микрокристаллитов возрастает примерно в 2 раза (см. таблицу). Данный факт противоречит соотношению Холла-Петча. Ранее [4] было выявлено, что значительное повышение микротвердости в Ті и $\mathrm{Zr}$ может быть вызвано образованием метастабильной барической $\omega$-фазы. Кроме того, из работ $[4,5]$ следует, что деформация может увеличивать не только долю омега-фазы, но также и ее термическую стабильность и твердость. Авторы [4] определили, что микротвердость $\omega$-фазы возрастает с $\sim 2400 \mathrm{MPa} \mathrm{(при}$ $\varepsilon=0$ ) до $\sim 4000 \mathrm{MPa}$, при $\varepsilon=76 \%$ (по сравнению с $\sim 1200 \mathrm{MPa}$ для недеформированной $\alpha$-фазы). Отметим, что в нашем случае величина истинной деформации несколько выше у образцов, продеформированных при $70^{\circ} \mathrm{C}$, по сравнению с образцами, продеформированными при комнатной температуре. Учитывая вышесказанное, следует заключить, что увеличение степени деформации, сопровождаемое незначительным нагревом, возможно, способствуют образованию более устойчивой и более твердой метастабильной $\omega$-фазы, которая в большем 
$a$
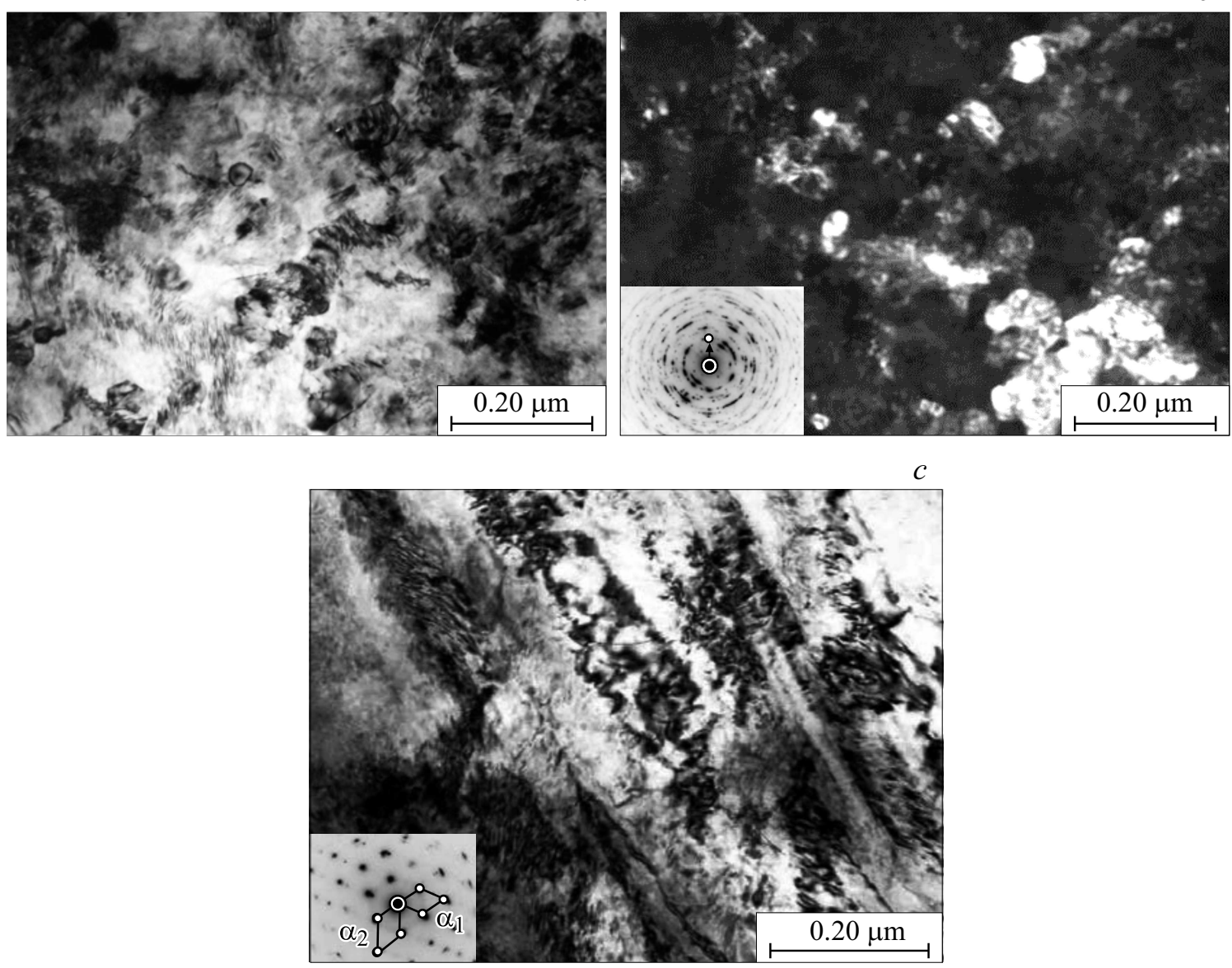

Рис. 2. Микроструктура $\mathrm{Zr}$, продеформированного на $\varphi=1080 \mathrm{deg}$ при комнатной температуре: $a-$ светлопольное изображение участка типичной структуры; $b-$ темнопольное изображение в $g_{\omega}=110$ оси зоны $[1 \overline{1} 0]_{\omega} ; c-$ светлопольное изображение участка с реечной структурой. Обратные решетки с осью зоны $[001]_{\alpha 1}$ и $[011]_{\alpha 2}$ (показаны схемой на рис. 2,c) [14].

объеме сохраняется после окончания эксперимента, не претерпевая обратного $\omega \rightarrow \alpha$ превращения. Как следствие, мы наблюдаем заметный прирост микротвердости, в то время как при увеличении зерна почти в 2 раза, в соответствии с законом Холла-Петча, должны были наблюдать заметное разупрочнение. Кроме того, более низкая твердость образца, испытанного при комнатной температуре, возможна вследствие того, что часть метастабильной $\omega$-фазы непосредственно в процессе измерения микротвердости (деформация алмазной пирамидкой) испытывает обратное $\omega \rightarrow \alpha$ превращение.

О большей стабильности $\omega$-фазы, образованной при $70^{\circ} \mathrm{C}$, свидетельствуют и электронно-микроскопические исследования, проведенные нами в предыдущей работе [6]. На рис. 1 представлена структура циркония, продеформированного в камере Бриджмена на $\varphi=1080 \mathrm{deg}$ при температуре $70^{\circ} \mathrm{C}$. Испытания при данной темпеpaтyре (рис. $1, a, b)$ в отличие от испытаний при комнатной температуре (рис. 2, $a, b$ ) приводят к появлению большого количества зерен с четкими большеугловыми границами, а темнопольные исследования показали, что это зерна $\omega$-фазы.
Можно предположить, что при незначительном повышении температуры барических испытаний на влияние таких термоактивируемых процессов деформации, как переползание и поперечное скольжение дислокаций $[7,8]$, которые облегчены у металлов с высокой ЭДУ (энергией дефекта упаковки) (у Zr ЭДУ $\left.=220 \mathrm{~mJ} / \mathrm{m}^{2}[9]\right)$, накладывается влияние диффузионных механизмов, а это, в свою очередь, приводит к ускоренной фрагментации и образованию кристаллитов с более совершенными межзеренными границами. Дополнительным стимулом к реализации релаксационных процессов, происходящих при теплой деформации под давлением, последствия которых мы наблюдаем, может стать квазинагрев. Известно, что интенсивная деформация при давлении способствует образованию большого количества дефектов, которые при аннигиляции приводят к локальному повышению температуры материала. О существовании таких процессов, в частности, говорится в работе [10]. Авторы утверждают, что сохранению теплоты в локальном участке и соответственно повышению температуры способствуют малая теплопроводность материала, высокий коэффи- 
циент упрочнения, особенности механизма деформации. Накопление неравновесных дефектов в результате интенсивной пластической деформации приводит к реализации высокотемпературных механизмов деформации $[11,12]$. В нашем случае при незначительном повышении температуры эксперимента, а также в результате дополнительного локального нагрева, упругие напряжения, возникающие на межфазной $\omega / \alpha$ границе вследствии накопления деформационных дефектов и фазового наклепа $\left(\Delta V^{\alpha \rightarrow \omega}=-0.023 \mathrm{~nm}^{3}\right)$, уменьшаются, что предотвращает перестройку $\omega \rightarrow \alpha$. В итоге благодаря активизации дополнительных механизмов превращения, приводящих к релаксации системы, образуется более стабильная $\omega$-фаза, сохраняющаяся после разгрузки в большем объеме, так как создаются энергетически устойчивые образования.

И в образце, нагруженном при комнатной температуре, и в образце, испытанном при температуре $70^{\circ} \mathrm{C}$, обнаруживаются участки реечной структуры со схожей морфологией (рис. 1, $c$ и рис. 2,c). Однако на микродифракции от участка с реечной структурой образца, испытанного при температуре $70^{\circ} \mathrm{C}$, присутствуют как рефлексы от $\alpha$-фазы, так и от $\omega$-фазы (рис. $1, c$ во вкладке) в отличие от образца, продеформированного при комнатной температуре. Электронно-дифракционный анализ показал, что $\alpha$ - и $\omega$-фазы находятся в ориентационном соотношении, аналогичные ориентационные соотношения наблюдали в [13]. Наличие $\omega$-фазы, несмотря на то, что ранее нами было показано [14], что обратный $\omega \rightarrow \alpha$-переход в процессе деформации при комнатной температуре реализуется первоначально в реечной структуре, доказывает, что в данной структуре при барической деформации, проходящей с незначительным повышением температуры $\left(0.04 T_{\text {melt }}\right)$, возникают дополнительные термодинамические предпосылки, способствующие повышению стабильности $\omega$-фазы и препятствующие обратному $\omega \rightarrow \alpha$-превращению при разгрузке. Наблюдаемая схожая морфология реечной структуры в обоих образцах еще раз подтверждает наше предположение, сделанное в предыдущей работе [6], о том, что в процессе цикла $\alpha \rightarrow \omega \rightarrow \alpha$-превращений происходит наследование струтурных дефектов, первоначально появляющихся при деформации исходной $\alpha$-фазы. Возникновение планарных дефектов в реечной структуре $\alpha$-фазы стимулирует зарождение $\omega$-фазы. При обратном $\omega \rightarrow \alpha$-превращении, как мы наблюдаем, дефекты сохраняются.

Твердость образцов, испытанных в камере Бриджмена при 100 и $300^{\circ} \mathrm{C}$, по значениям приближается к твердости образца, испытанного при комнатной температуре (см. таблицу), а не снижается, как можно было бы ожидать, вследствии происходящей постдинамической рекристаллизации, возрастания размеров зерен и обратного $\omega \rightarrow \alpha$-превращения. Дополнительный вклад в повышенние твердости возможен, как мы предполагаем, из-за наличия в структуре более твердой $\omega$-фазы.

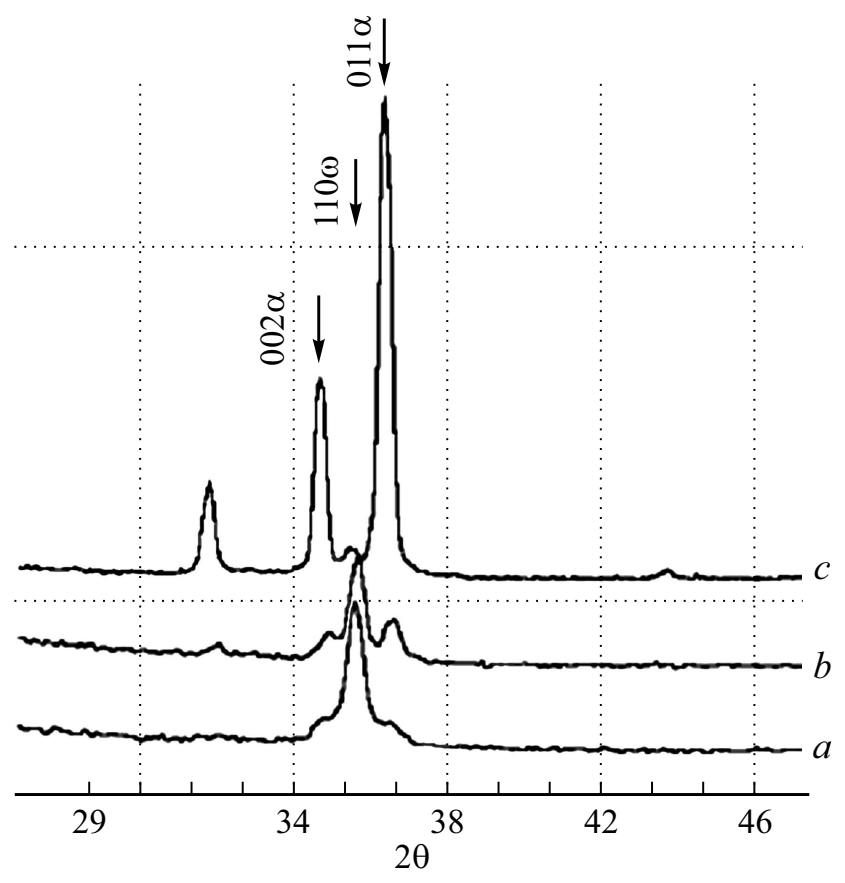

Рис. 3. Дифрактограммы $\mathrm{Zr}$, продеформированного на $\varphi=1080 \operatorname{deg}$ при: $a-70 ; b-100 ; c-300^{\circ} \mathrm{C}$.

Действительно, в работе [15] показано, что метастабильная фаза устойчива до $300^{\circ} \mathrm{C}$. Проведенные нами электронно-микроскопические исследования и рентгеноструктурный анализ [6] испытанных при повышенных температурах образцов циркония выявили, что $\omega$-фаза сохраняется во всех образцах и после окончания эксперимента (рис. 3). И это несмотря на то, что интенсивная деформация, как было показано ранее, приводит к ускоренной реализации высокотемпературных процессов. Следовало бы ожидать повышения объемной доли обратного $\omega \rightarrow \alpha$-превращения, так как данный фазовый переход должен происходить в интервале от 150 до $200^{\circ} \mathrm{C}$. Мы можем предположить, что к рассматриваемому выше механизму, приводящему к стабилизации барической $\omega$-фазы, а именно - образование устойчивых межфазных границ, добавляются, как указано в [16], реализуемые при больших деформациях и высоких температурах ориентированное зарождение и рост структурных составляющих. В нашем случае это относится только к барической $\omega$-фазе, что приводит вследствии ее сильной анизотропности к повышению стабильности и сохранению $\omega$-фазы при температурах выше температуры фазового перехода.

Известно, что цирконий при температуре выше $250^{\circ} \mathrm{C}$ начинает поглощать водород с образованием гидридов типа $\delta-\mathrm{ZrH}_{2-x}$ [17]. Следовательно, высокая твердость образцов, испытанных в камере Бриджмена при $300^{\circ} \mathrm{C}$, может быть обусловлена именно присутствием гидридов вследствии дисперсионного упрочнения, так как процесс образования гидридов сопровождается большим объемным расширением (объем фазы $\delta$-гидрида пример- 

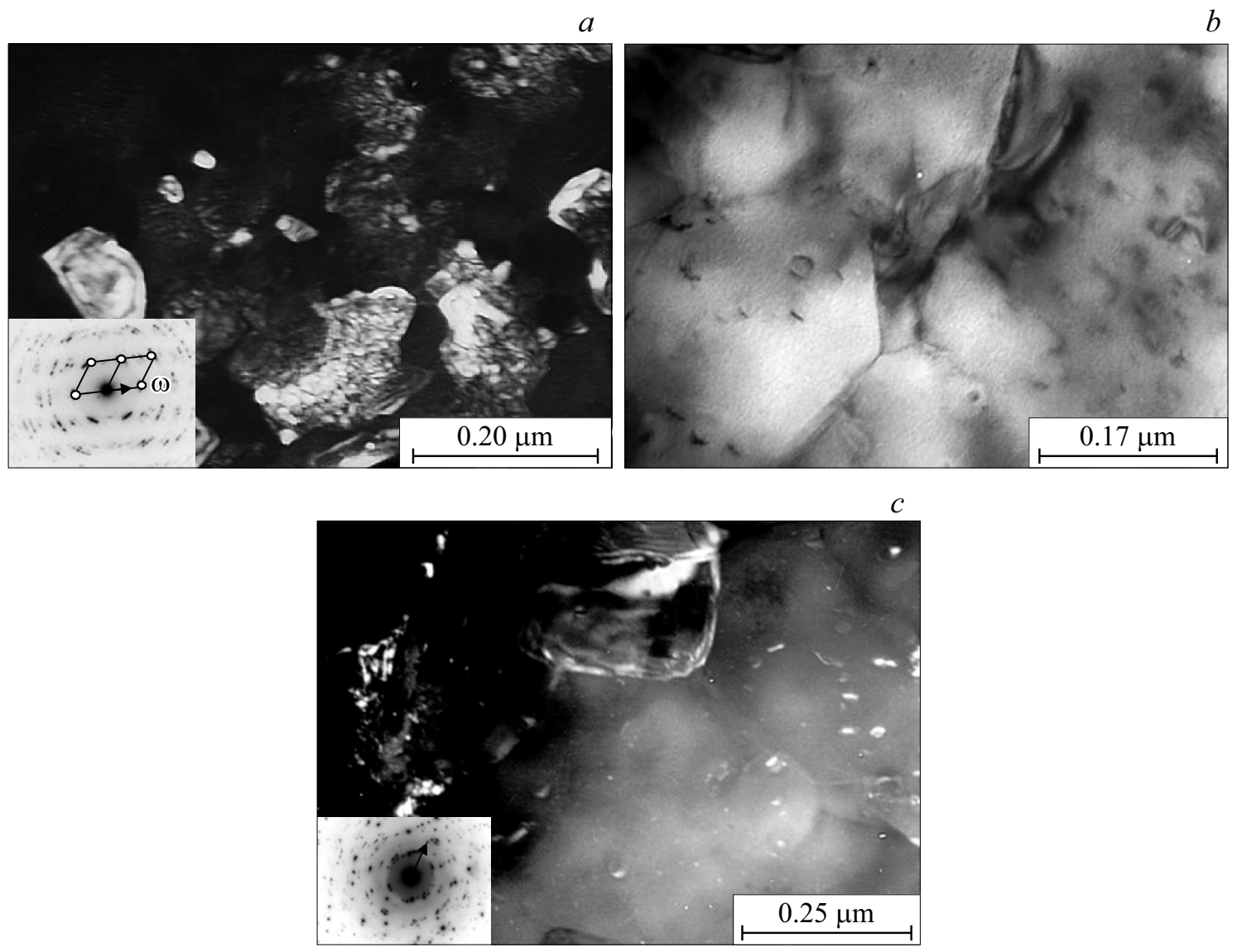

Рис. 4. Микроструктура $\mathrm{Zr}$, продеформированного на $\varphi=1080 \mathrm{deg}$ при: $a-100^{\circ} \mathrm{C}$, темнопольное изображение в рефлексе $g_{\omega}=110$ оси зоны $[001]_{\omega} ; b-300^{\circ} \mathrm{C}$, светлопольное изображение; $c-300^{\circ} \mathrm{C}$, темнопольное изображение в рефлексе $g=(021) \omega$ (указано стрелкой).

но на $17 \%$ больше, чем исходная циркониевая матрица) [18], и, кроме того, гидриды циркония значительно тверже $\alpha$-фазы [19]. На электронно-микроскопических снимках структуры образца циркония, испытанного при температуре $300^{\circ} \mathrm{C}$, действительно можно наблюдать контраст типа „кофейного зерна“ (рис. 4,b), который свидетельствует о наличии полей упругих напряжений, возникающих вследствии когерентных выделений в матрице частиц линзовидной формы. Из-за малого размера частиц на микродифракционных изображениях, рефлексы, соответствующие гидридной фазе, не удалось идентифицировать, но на темнопольном изображении, полученном в рефлексе $(021)_{\omega}$ (рис. $\left.4, b\right)$, наблюдаются частицы гидрида циркония, выделившиеся в матрице.

\section{Заключение}

Исследования образцов псевдомонокристаллического циркония, испытанных в камере Бриджмена при одинаковой схеме нагружения, но при различных температурах, показали существенное различие в структурно-фазовом состоянии и механических свойствах.
Выявлены факторы, способствующие сохранению в структуре образцов, продеформированных при 70 и $100^{\circ} \mathrm{C}$, значительного количества метастабильной фазы, а именно образование устойчивых межфазных границ и возможность ориентированного зарождения и роста $\omega$-фазы.

В псевдомонокристаллическом цирконии, испытанном при $300^{\circ} \mathrm{C}$, обнаружены дисперсные частицы гидрида циркония переменного состава $-\delta-\mathrm{ZrH}_{2-x}$, которые обусловливают повышенную твердость.

\section{Благодарности}

Электронно-микроскопическое исследование деформированных образцов циркония проводили на микроскопе JEM-200CX в отделе электронной микроскопии ЦКП „Испытательный центр нанотехнологий и перспективных материалов“ Института физики металлов УрО РАН.

\section{Финансирование работы}

Работа выполнена в рамках государственного задания по теме „Структура“ (№ AААА-А18-118020190116-6) 
при частичной финансовой поддержке Комплексной программы УрО РАН № 18-10-2-39.

\section{Конфликт интересов}

Авторы заявляют, что у них нет конфликта интересов.

\section{Список литературы}

[1] Самойлов А.Г. Тепловыделяющие элементы ядерных реакторов: Учеб. пособие для вузов. М.: Энергоатомиздат, 1985. $224 \mathrm{c}$.

[2] Tonkov E.Yu. Phase diagrams of elements at high pressure. M.: Science, Home edition of Physical and mathematical literature, 1979. 192 p. (in Russian) [Тонков Е.Ю. Фазовые диаграммы элементов при высоком давлении. М.: Наука, Физматлит, 1979. 192 c.]

[3] Degtyarev M.V., Chashchukhina T.I., Voronova L.M., Davydova L.S., Pilyugin V.P. // Phys. Metal. Metallography. 2000. Vol. 90. N 6. P. 604-612.

[4] Бланк В.Д., Веллер М.Е., Коняев Ю.С., Эстрин Э.И. // ФММ. 1979. Т. 47. Вып. 5. С. 1109-1111.

[5] Kaveh Edalati, Zenji Horita, Shunsuke Yagi // Mater. Sci. Engineer. A. 2009. Vol. 523. P. 277-281.

[6] Егорова Л.Ю., Хлебникова Ю.В., Пацелов А.М., Пилюгин В.П. // Вестник МГТУ им. Г.И. Носова. 2018. Т. 16. № 3. C. 120-126.

[7] Рекристаллизация металлов и сплавов: монография / С.С. Горелик, С.В. Добаткин, Л.М. Капуткина. М.: МИСИС, 2005. $432 \mathrm{c.}$

[8] Механические свойства металлов. Учебник для вузов. 3-е издание переработанное и дополненное / В.С. Золоторевский. М.: МИСИС, 1998. 440 с.

[9] Свойства элементов: Справ. изд. / Под ред. Дрица М.Е. М.: Металлургия, 1985. 672 с.

[10] Тейтель Е.И. // Физика и техника высоких давлений. 2014. T. 24. № 3-4. C. 5-25.

[11] Kondrat'ev V.V., Gapontsev V.L. // Phys. Metal. Metallograph. 2002. Vol. 94. P. S131-S138.

[12] Колобов Ю.Р., Валиев Р.З. Колобов Ю.Р., Валиев Р.З., Грабовеикая Г.П., Жиляев А.П., Дударев Е.Ф., Иванов К.В., Иванов М.Б., Кашин О.А., Найденкин Е.В. Зернограничная диффузия и свойства наноструктурных материалов. Новосибирск: Наука, 2001. 232 с.

[13] Rabinkin M. Talianker O. Botstein O. // Acta Metallrgica. 1981. Vol. 29. P. 691-698.

[14] Egorova L.J., Khlebnikova Y.V., Pilyugin V.P. // Lett. Mater. 2016. Vol. 6. N 3. P. 237-242.

[15] Wenk H.-R., Kaercher P., Kanitpanyacharoen W., Zepeda-Alarcon E., Wang Y. // Phys. Rev. Lett. 2013. Vol. 111. P. 195701.

[16] Ghosh P., Renk O., Pippan R. // Mater. Sci. Engineer. A. 2017. Vol. 684. P. 101-109.

[17] Фролов В.В. Учебное пособие для машиностроительных специальностей вузов. 3-е изд., перераб. и доп. М.: Высшая школа, 1986. 543 с.

[18] Jiujun Xua, San-Qiang Shib. // J. Nucl. Mater. 2004. Vol. 327. P. $165-170$.

[19] Yamanaka S., Yoshioka K., Uno M., Katsura M., Anada H., Matsuda T., Kobayashi S. // J. Alloys Compounds. 1999. Vol. 293-295. P. 23-29. 